GA-A23469

\title{
REAL-TIME CONTROL OF DIII-D PLASMA DISCHARGES USING A LINUX ALPHA COMPUTING CLUSTER
}

\author{
B.G. PENAFLOR, J.R. FERRON, M.L. WLAKER, D.A. PIGLOWSKI, \\ and R.D. JOHNSON
}




\section{DISCLAIMER}

This report was prepared as an account of work sponsored by an agency of the United States Government. Neither the United States Government nor any agency thereof, nor any of their employees, makes any warranty, express or implied, or assumes any legal liability or responsibility for the accuracy, completeness, or usefulness of any information, apparatus, product, or process disclosed, or represents that its use would not infringe privately owned rights. Reference herein to any specific commercial product, process, or service by trade name, trademark, manufacturer, or otherwise, does not necessarily constitute or imply its endorsement, recommendation, or favoring by the United States Government or any agency thereof. The views and opinions of authors expressed herein do not necessarily state or reflect those of the United States Government or any agency thereof. 


\title{
REAL-TIME CONTROL OF DIII-D PLASMA DISCHARGES USING A LINUX ALPHA COMPUTING CLUSTER
}

\author{
B.G. PENAFLOR, J.R. FERRON, M.L. WLAKER, D.A. PIGLOWSKI, \\ and R.D. JOHNSON
}

This is a preprint of a paper presented at the 21st Symposium on Fusion Technology, September 11-15, 2000 in Madrid, Spain and to be published in Fusion Design and Engineering.

\author{
Work supported by \\ the U.S. Department of Energy under \\ Contract No. DE-AC03-99ER54463
}




\section{ABSTRACT}

This paper describes an upgrade for the real-time computing system responsible for monitoring and controlling plasma discharges in the DIII-D tokamak [1] at General Atomics (GA). The current system employs six CSPI i860 VME format processors working in parallel to acquire data in real-time and perform feed back control of plasma shape and position parameters.

Work has commenced on integration of a new computing system based on commonly available PCI bus based processors that communicate over the 2 gigabit per second Myrinet [2] network. The new system will greatly improve the processing power available to the algorithms required for computing plasma equilibrium reconstructions in real-time. A factor of twenty anticipated performance increase will allow for improved accuracy and frequency response for plasma shape estimation and control. The migration from VME to PCI Myrinet computer clustering will improve the data acquisition capabilities by opening up access to additional DIII-D temperature and density diagnostics. The upgrade will increase the inter-processor communication speed and provide the flexibility to integrate additional processors to match the cost and computing needs of the tokamak research program. 


\section{THE PRESENT DIII-D PLASMA CONTROL SYSTEM}

DIII-D plasma discharges are controlled using the real-time digital Plasma Control System (PCS) developed at GA [3]. The PCS has evolved over the years into a robust and highly flexible system used to control not only plasma shape and position parameters but also total current, plasma density, stored energy and radiated power.

The original design plan for shape identification in the digital PCS focused on linearization about a target discharge of the response of shape parameters to diagnostic measurements [4]. The flexibility of the digital system allowed execution of a real-time equilibrium reconstruction algorithm (RTEFIT) instead, providing more accuracy and flexibility [5]. RTEFIT combined with a conventional Proportional Integral Derivative (PID) controller is now in routine use for DIII-D shape control. Under development is a multiple-input multiple-output (MIMO) model based shape controller to replace the PID controller [6]. This shape identification method combined with the MIMO controller requires considerable processing power and can be improved if additional power is available. 


\section{MOTIVATIONS FOR AN UPGRADE}

While the present PCS has achieved considerable capacity, it has come close to reaching its limits for expandability. In order to continue to meet the needs of the DIII-D research program and to keep DIII-D at the forefront of worldwide fusion research an upgrade of the PCS has become necessary.

Among the future needs [7] of the DIII-D research program are: 1) advanced tokamak discharges involving complex coupling of internal parameter profiles and improved confinement, 2) operation at high beta, which is expected to require active feedback stabilization of MHD instabilities such as resistive wall modes and neoclassical tearing modes, 3) current profile control and, 4) pressure profile control.

Fulfilling all of these needs will require certain improvements to the present capabilities of the PCS including: 1) enhancements to the isoflux [5] control capability, 2) improvements to the accuracy of the RTEFIT calculations, 3) improvements to the frequency response for shape control required for a good implementation of the MIMO capability and, 4) further development of the MIMO capability to include current density and pressure profile control. 


\section{DESCRIPTION OF THE UPGRADE SYSTEM}

The upgrade of the PCS is focused on providing increased cpu power by incorporating PCI based Alpha 21264 processors to be used for real-time computations and feedback control. The new Alpha processors will eventually replace and eliminate the dependence on the present i860 processors. In order to satisfy the real-time requirements of the PCS, the Alpha processors will be running a version of the Linux kernel containing customizations which will allow the PCS real-time processes to employ $100 \% \mathrm{cpu}$ utilization during DIII-D plasma discharges. The computer interconnect solution is being provided by 2 gigabit Myrinet PCI network cards and switches. The data acquisition hardware upgrades will include front panel data port digitizer modules which plug into a VME bus.

Recent problems in maintaining the existing i860 hardware due to dwindling driver and software support, a limited set of choices for fast VME computers and the higher expense of VME systems have resulted in a switch to the PCI bus for the PCS upgrade. The migration from a VME based real-time system to a primarily PCI based system represents a major design change for the PCS. The move away from VME to the more popular and better supported PCI bus opens up a greater range of options for choice of processors, operating systems, digitizers, analog and digital output modules and other related hardware.

The 64 bit Alpha computing platform was chosen because of its unmatched performance, Linux compatibility, and availability of quality compilers. A $667 \mathrm{MHz}$ 21264 Alpha system from DCG computers is to be installed as the first computer for the PCS upgrade. The new Alpha contains four megabytes of cache and boasts a specfp 95 (floating point performance rating) of 65 which is roughly twice that of the fastest Intel Pentium and at least 16 times faster than the $40 \mathrm{MHz}$ i860 it is replacing. A UP2000 motherboard provides the option of adding a second onboard processor to the computer system and also provides a high memory bandwidth with memory transfer rates in excess of 2.6 gigabytes per second. The initial upgrade system has been fitted with 512 megabytes of ram, an 18 gigabyte hard drive and contains two 64 bit and four 32 bit PCI expansion slots

RedHat Linux is being used as the foundation for a customized real-time operating system. Linux was chosen over other possible operating systems for a number of reasons including: 1) availability of source code making it possible to implement a custom realtime operating solution for the PCS upgrade. 2) support for a wide variety of computing 
hardware including Alpha, Intel and PowerPC processors. 3) proven stability. 4) growing acceptance in industry and the scientific community 5) zero cost. A real-time Linux kernel from FSMlabs was strongly considered, but a $15 \mathrm{~ms}$ worst case interrupt latency was still too high to meet the strict requirements of the PCS. Instead a GA customized solution was created for obtaining real-time performance using Linux. The solution involves simple changes to the Linux kernel to modify the scheduler and completely disable the effect of all interrupts. The custom kernel provides the means for a PCS process to command $100 \%$ utilization of the processor and exhibit the type of real-time behavior necessary for performing plasma control.

A number of factors have contributed in making Myrinet the choice for connecting the real-time computers in the upgrade. Myrinet is a $2 \mathrm{Gbit} / \mathrm{s}$ network architecture designed for implementing parallel processing systems. Its key advantages include: 1) interface boards available in a variety of packages including PCI and PMC, 2) relatively reasonable cost, 3) availability of fiber optic interfaces appropriate for connecting to remote regions of the laboratory, 4) availability of 64 bit PCI bus boards for maximum transfer speed, 5) open architecture provided by a programmable communications processor on the interface board, 6) on board DMA engine allowing access to data without requiring intervention of the operating system, 7) switched fabric architecture rather than a common bus, 8) availability of multi-port switches which make the network essentially infinitely expandable.

New digitizers added to the system will use "front panel data port" (FPDP) for communication to a VME PMC carrier board. The PMC carrier would contain a Myrinet communications processor board. Thus, a group of digitizers would appear as a node on the real-time network. Data would be transferred from the digitizers to any requesting real-time processor by the communication processor. 


\section{IMPLEMENTATION}

The interim solution for connecting the first Alpha computer to the existing VME based system involves incorporation of a VME Pentium computer with a Myrinet PMC card which will be used to communicate data between the Alpha computer and the existing PCS i860 computers (Fig. 1). The VME Pentium computer will be running a modified Linux kernel to enable real-time process execution. The mixed i860, Pentium and Alpha real-time computing system will provide a means for continuing use of the existing system concurrent with development and testing of the new hardware and software for the upgrade. The intermediate system will also be used to offload some of the work now being performed by the i860s to the more powerful Alpha processor. Portions of the real-time equilibrium reconstruction code will be migrated to run on the new computer, along with development of new code to perform tokamak safety factor (q) profile calculations.

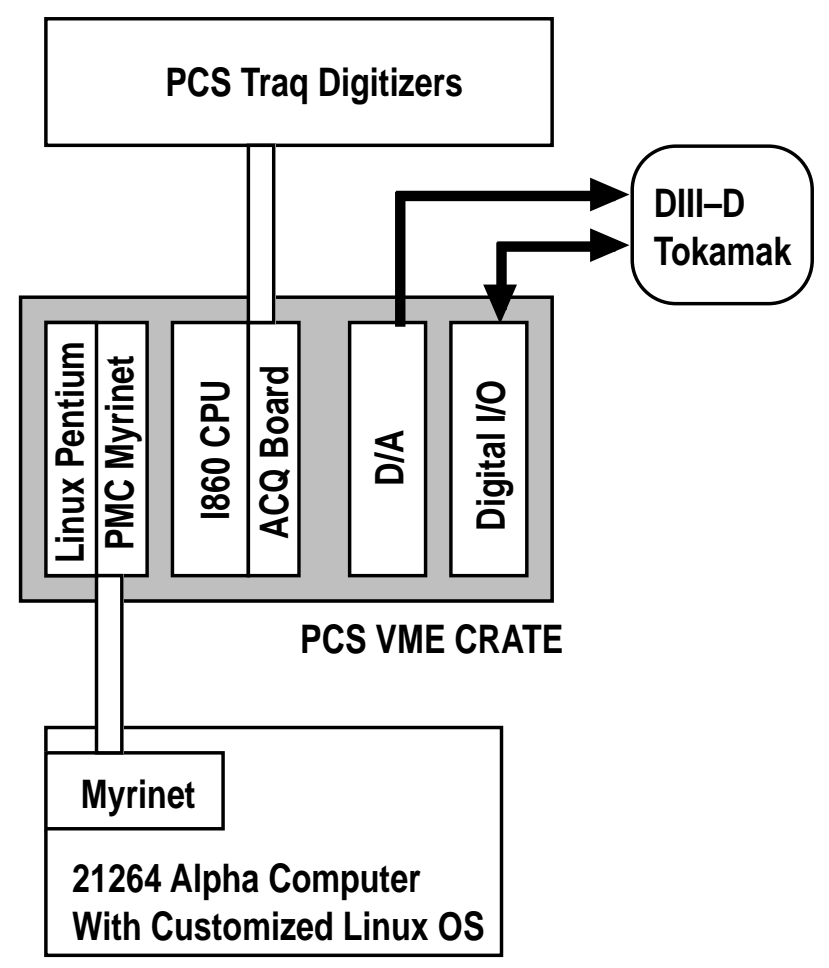

Fig. 1. Intermediate implementation of PCS upgrade. 
The full upgrade system (Fig. 2) will utilize between four to seven Alpha computers, and eliminate use of the VME based i860 computers. It is also possible that computers other than the Alpha such as less expensive Intel Pentiums or PowerPCs could be added at some point to handle PCS real-time processes not requiring the high performance of the Alphas. The use of a Myrinet switch and interface cards will allow for eventual connections to other computers located within the DIII-D facility including the Thomson and CER diagnostics.

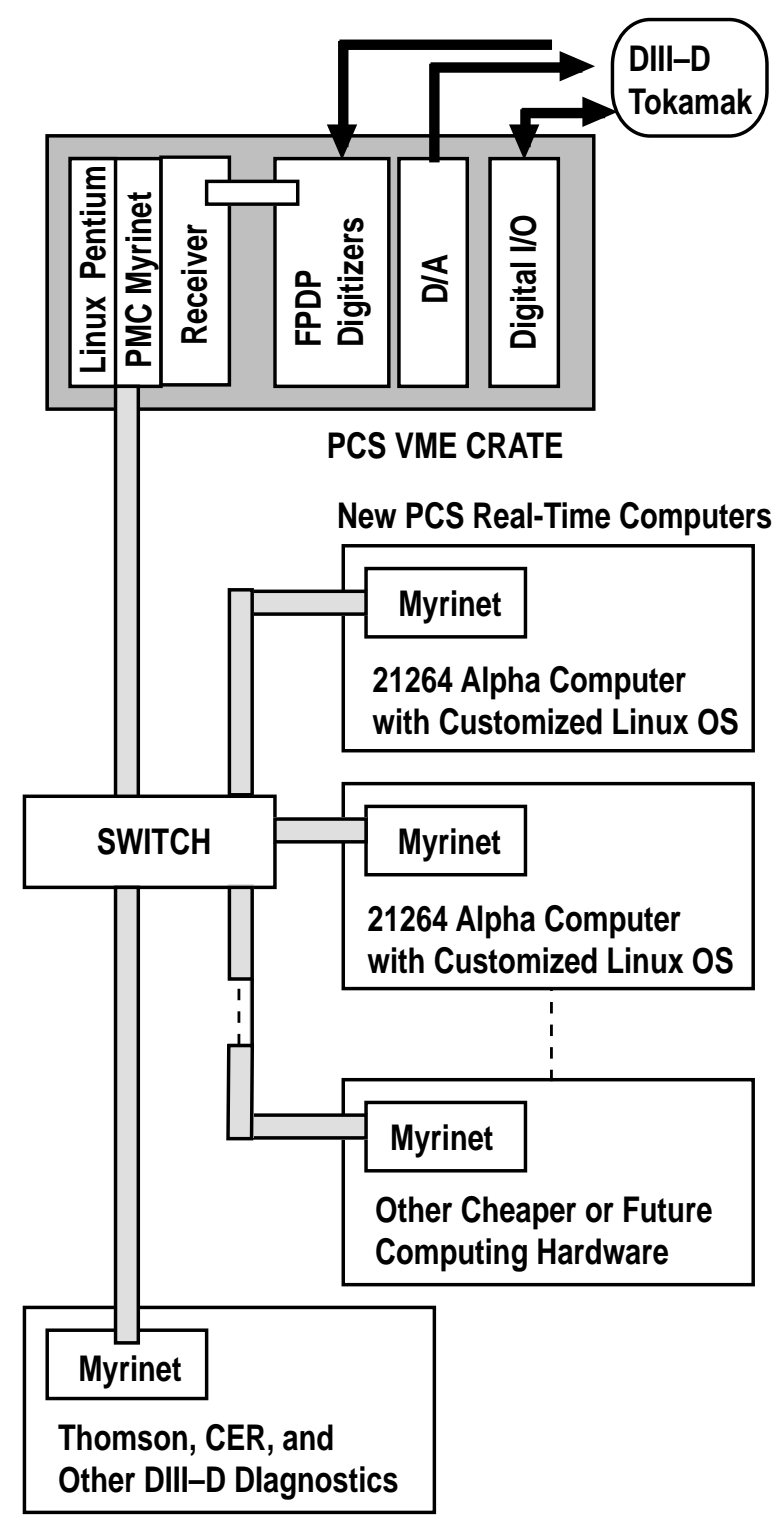

Fig. 2. Full implementation of the PCS upgrade. 


\section{CONCLUSION}

A specific plan for implementation of the PCS upgrade has been proposed with work on the new real-time subsystem already well underway. The goal is to make gradual modifications to the existing PCS software and hardware with minimal disruptions to DIII-D operations. The large investment in software developed for the PCS over the past decade will be maintained by using as much of the existing code as possible for the upgrade system. Integration of the first Alpha upgrade computer into the existing system has been targeted for late 2000. Installation of a full featured upgrade system with multiple Alpha computers assuming responsibility for execution of the PCS real-time software and incorporation of new data acquisition, analog and digital output hardware is scheduled for the late 2001 time frame. 


\section{REFERENCES}

[1] J.L. Luxon, L.G. Davis, Fusion Technol. 8 (1985) 441.

[2] Myricom, Inc., 325 N. Santa Anita Ave. Arcadia, CA 91006, Telephone: 626-8215555, www.myri.com.

[3] B.G. Penaflor, D.A. Piglowski, J.R. Ferron, M.L. Walker, "Current Status of DIII-D Real-Time Digital Plasma Control," 11th IEEE NPSS Real Time Conference Santa Fe (1999) 218.

[4] J.R. Ferron, A.G. Kellman, G.R. McKee, T.H. Osborne, P. Petrach, T.S. Taylor, J. Wight, "An Advanced Plasma Control System for the DIII-D Tokamak," Proc. 14th IEEE/NPSS Symp. on Fusion Engineering, IEEE (San Diego, California, 1991) Vol. II (1992) 761.

[5] J.R. Ferron, M.L. Walker, L.L. Lao, H.E. St.John, D.A. Humphreys, J.A. Leuer, "Real Time Equilibrium Reconstruction for Tokamak Discharge Control," Nuclear Fusion, Vol. 38, No. 7 (1998) 1055.

[6] M.L. Walker, D.A. Humphreys, J.A. Leuer, J.R. Ferron, B.G. Penaflor, "Implementation of Model-Based Multivariable Control on DIII-D," This Conference.

[7] T.S. Taylor, Plasma Phys Conf. Fusion 39, B47 (1997). 


\section{ACKNOWLEDGMENT}

Work supported by U.S. Department of Energy under Contract No. DE-AC0399ER54463. 